\title{
Bronchial Thermoplasty-Induced Acute Airway Effects Assessed with Optical Coherence Tomography in Severe Asthma
}

\author{
Annika W.M. Goorsenberg ${ }^{a} \quad$ Julia N.S. d'Hooghe ${ }^{a}$ Daniel M. de Bruin ${ }^{b}$ \\ Inge A.H. van den Berk ${ }^{\mathrm{c}}$ Jouke T. Annema ${ }^{\mathrm{a}}$ Peter I. Bonta ${ }^{\mathrm{a}}$ \\ a Department of Respiratory Medicine, Academic Medical Center, University of Amsterdam, Amsterdam, \\ The Netherlands; ${ }^{b}$ Department of Biomedical Engineering \& Physics Radiology, Academic Medical Center, \\ University of Amsterdam, Amsterdam, The Netherlands; ' Department of Radiology, Academic Medical Center, \\ University of Amsterdam, Amsterdam, The Netherlands
}

\section{Keywords}

Bronchial thermoplasty · Imaging · Severe asthma · Airway remodeling

\section{Abstract}

Background: Bronchial thermoplasty (BT) is an endoscopic treatment for severe asthma targeting airway smooth muscle (ASM) with radiofrequent energy. Although implemented worldwide, the effect of BT treatment on the airways is unclear. Optical coherence tomography (OCT) is a novel imaging technique, based on near-infrared light, that generates high-resolution cross-sectional airway wall images. $\mathbf{O b}$ jective: To assess the safety and feasibility of OCT in severe asthma patients and determine acute airway effects of BT by OCT and compare these to the untreated right middle lobe (RML). Methods: Severe asthma patients were treated with BT (TASMA trial). During the third BT procedure, OCT imaging was performed immediately following BT in the airways of the upper lobes, the right lower lobe treated 6 weeks prior, and the untreated RML. Results: 57 airways were imaged in 15 patients. No adverse events occurred. Three distinct OCT patterns were discriminated: low-intensity scattering pattern of (1) bronchial and (2) peribronchial edema and (3) high-intensity scattering pattern of epithelial sloughing. (Peri)bronchial edema was seen in all BT-treated airways, and less pronounced in only 1/3 of the RML airways. These effects extended beyond the ASM layer and more distal than the directly BT-treated areas and were reduced, but not resolved, after 6 weeks. Epithelial sloughing occurred in $11 / 14$ of the BT-treated airways and was absent in untreated RML airways. Conclusions: Acute BT effects can be safely assessed with OCT and 3 distinct patterns were identified. The acute effects extended beyond the targeted ASM layer and distal of directly BT-treated airway areas, suggesting that BT might also target smaller distal airways.

C 2018 The Author(s)
Published by S. Karger AG, Basel

\section{Introduction}

Bronchial thermoplasty (BT) is a relatively new nonpharmacological treatment for severe asthma patients based on the delivery of radiofrequent energy to the airways [1]. BT was designed to target airway remodeling of

\begin{tabular}{ll}
\hline KARGER & $\begin{array}{l}\text { (c) } 2018 \text { The Author(s) } \\
\text { Published by S. Karger AG, Basel }\end{array}$ \\
E-Mail karger@karger.com & $\begin{array}{l}\text { This article is licensed under the Creative Commons Attribution- } \\
\text { NonCommercial-NoDerivatives 4.0 International License (CC BY- } \\
\text { NC-ND) (http://www.karger.com/Services/OpenAccessLicense). } \\
\text { Usage and distribution for commercial purposes as well as any dis- } \\
\text { tribution of modified material requires written permission. }\end{array}$
\end{tabular}

Peter I. Bonta, MD, PhD, Pulmonologist

Department of Respiratory Medicine, F5-144

Academic Medical Center, University of Amsterdam

Meibergdreef 9, NL-1105 AZ Amsterdam (The Netherlands)

E-Mail p.i.bonta@amc.uva.nl 


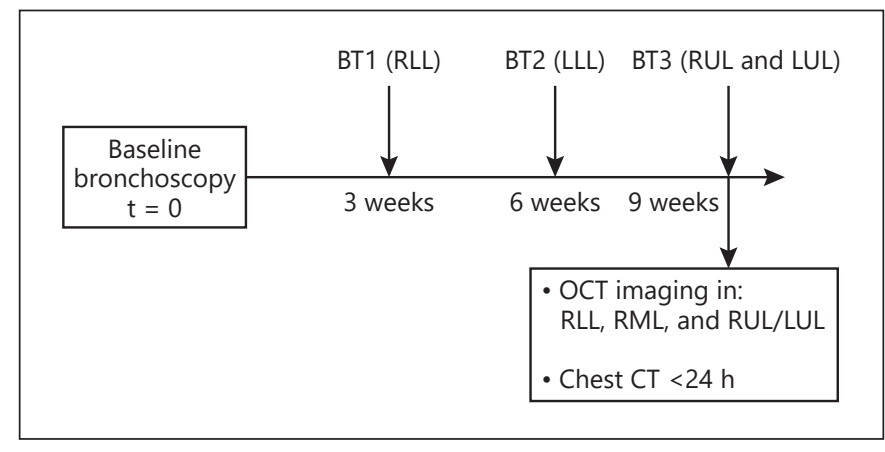

Fig. 1. Flowchart of the study design. BT1, bronchial thermoplasty session 1, treatment of the right lower lobe (RLL); BT2, bronchial thermoplasty session 2, treatment of the left lower lobe (LLL); BT3, bronchial thermoplasty session 3, treatment of the right upper lobe (RUL) and left upper lobe (LUL); OCT, optical coherence tomography; RML, right middle lobe; $\mathrm{CT}$, computed tomography.

the larger airways by reducing the airway smooth muscle (ASM) mass by thermal ablation. Besides preclinical studies, in recent years a reduction of the ASM mass has been reported in airway biopsies after BT treatment [25]. Randomized trials have shown that BT is safe and effective in reducing exacerbation rates in asthmatic patients and improving asthma-related quality of life [6-8]. However, these trials were not able to define a specific asthma phenotype that responds best to BT. Studies including the TASMA trial (ClinicalTrials.gov No.: NCT02225392) are underway to unravel the mechanism of action of BT to further define which phenotype of severe asthma patients might benefit most.

There is limited data available on the acute effects of BT on the airway wall. Two recent studies described radiological patterns including peribronchial consolidations after BT detected on computed tomography (CT) $[9,10]$. However, the limitation in resolution makes it difficult to assess the exact nature and extent of acute effects in the airway wall. Optical coherence tomography (OCT) is a novel imaging technique in which near-infrared light is used to obtain cross-sectional, high-resolution images of the airway wall over a length of $5.4 \mathrm{~cm}$ [11-13]. Previous studies have shown a high correlation between histology and OCT for assessing and quantifying the airway wall $[14,15]$. So far, in severe asthma, OCT has only been reported in 2 patients [16].

The aim of this study was to: (1) assess the safety and feasibility of OCT in a severe asthmatic patient cohort; (2) identify the acute effects of BT on the airway wall by OCT, and (3) compare these effects to the untreated right mid- dle lobe (RML). We hypothesized that OCT is able to distinguish acute effects in BT-treated airways from non-BTtreated airways and that these effects resolve with time.

\section{Methods}

Design and Subjects

This observational study, conducted between July 2014 and February 2017, is part of the TASMA "Unravelling Targets of Therapy in Bronchial Thermoplasty in Severe Asthma" trial. The Medical Ethics Committee of the AMC provided ethical approval (NL45394.018.13). The study design is shown in Figure 1. Patients with severe refractory asthma according to the World Health Organization (WHO) guidelines and the Innovative Medicine Initiative (IMI) criteria were included in the TASMA trial $[17,18]$. Written informed consent was provided.

\section{Bronchial Thermoplasty}

15 patients were treated with BT by using the Alair System (Boston Scientific, USA) according to the current standard [1921] and sedated using remifentanil/propofol [22]. Patients were treated with $50 \mathrm{mg}$ of prednisolone 3 days before treatment, on the day of the procedure itself and 1 day thereafter. During the first procedure, the right lower lobe (RLL) was treated, during the second procedure the left lower lobe, and finally both upper lobes. The RML remained untreated.

\section{Imaging}

During the third BT procedure, OCT imaging was performed using a C7-XR St. Jude Medical Inc. system interfaced with a C7 Dragonfly catheter (diameter $0.9 \mathrm{~mm}$; St. Jude Medical Inc., St. Paul, MN, USA). Directly after the BT procedure, the OCT catheter was inserted through the working channel of the bronchoscope using a guide sheath in the following (sub)segmental airways: first, 2 airways of the 6 weeks earlier treated RLL; subsequently, the untreated RML; and finally, 1 airway of the BT-treated left or right upper lobe. The proximal marker of the catheter, situated $5.4 \mathrm{~cm}$ from the distal tip, was inserted until the level of the segmental carina and was used as reference point. In each airway, an automated pullback, during which the OCT system automatically images the airway segment over a length of $5.4 \mathrm{~cm}$, was performed twice. Low-dose chest CT was routinely performed directly or 1 day after the last procedure and airway reconstructions were made by an experienced chest radiologist using Impax Volume Viewing software (Agfa HealthCare, Mortsel, Belgium).

\section{OCT Image Analysis}

All OCT images and pullbacks were evaluated by one experienced OCT observer and confirmed by a second blinded observer and compared to normal [15]. A set of OCT patterns detected directly after $\mathrm{BT}$ in the airway wall were identified. The presence or absence of these patterns was assessed for all imaged airways. Lowintensity scattering, depicted as black areas, within the airways corresponds to air, while within the airway wall itself the black areas correspond to fluid (i.e., edema or blood vessels). The first highintensity scattering yellow layer of the airway wall corresponds to the mucosa and contains the epithelium and lamina propria as described by d'Hooghe et al. [15]. 
Table 1. Baseline characteristics

\begin{tabular}{lc}
\hline Subjects, $n$ & 15 \\
Age, years & $38.1 \pm 13.6$ \\
Male/female gender & $1 / 14$ \\
FEV1 before BD, \% & $91.3 \pm 23.0$ \\
FEV1 after BD, \% & $103.9 \pm 19$ \\
LABA dose, $\mu$ g/day salmeterol equivalents & $153 \pm 90.5$ \\
ICS dose, $\mu$ g/day fluticasone equivalents & $1,167 \pm 497$ \\
Patients on maintenance use of OCS, $n$ & 6 \\
Oral prednisone dose, mg/day & $12.5 \pm 6.1$ \\
Added bronchoscopy time for OCT imaging, min & $9.51 \pm 1.17$ \\
Airways imaged, $n$ & \\
$\quad$ Left upper lobe or right upper lobe & 14 \\
$\quad$ Right lower lobe & 29 \\
$\quad$ Middle lobe & 14 \\
\hline
\end{tabular}

Presented data are shown as $n$ or mean \pm SD. FEV1, forced expiratory volume in 1 second before and after bronchodilation (BD) expressed in \% of predicted; LABA, long-acting beta-2-agonist; ICS, inhaled corticosteroids; OCS, oral corticosteroids; OCT, optical coherence tomography.

\section{Statistical Analysis}

GraphPad Prism version 5.01 (GraphPad Software Inc, San Diego, CA, USA) was used to calculate descriptive statistics. For normal distributed variables, a mean and standard deviation (SD) were given. Categorical characteristics were shown as a number and percentage.

\section{Results}

A total of 57 airways were imaged in 15 patients. Baseline characteristics are shown in Table 1. There were no adverse events reported related to OCT imaging and the added bronchoscopy time was $9.51( \pm 1.17) \mathrm{min}$.

Three distinctive patterns were identified by OCT (Fig. 2; online suppl. video 1; for all online suppl. material, see www.karger.com/doi/10.1159/000491676): a low-intensity scattering pattern within the (sub)mucosal layer of the airway wall, corresponding to bronchial wall edema (Fig. 2c); a broader pattern of low-intensity scattering beyond the cartilage of the airway wall corresponding to peribronchial edema (Fig. 2c); and a third high-intensity scattering pattern of epithelium sloughing in which the epithelium is (partly) disconnected from the airway wall (Fig. 2d).

The first pattern, bronchial wall edema, was seen in almost all airways imaged directly after BT (13/14; 93\%). Both peribronchial edema and epithelial sloughing were detected in 11/14 (79\%) airways (Fig. 2; Table 2). Both patterns of edema (peribronchial and bronchial) extend- ed more distal than the directly BT-treated parts of the airways, which is limited to $\sim 2-3 \mathrm{~mm}$ or larger diameter airways (Fig. 2a), indicating an acute BT effect more distal than the directly BT-treated areas. Furthermore, peribronchial edema extended beyond the cartilage rings of the airway wall, indicating an effect deeper than the BTtargeted ASM layer (Fig. 2c). Epithelial sloughing and edema (both peribronchial and bronchial) coincided directly after BT in almost all BT-treated airways, although epithelial sloughing occurred mainly in the proximal part of the airway, where the BT electrodes made contact with the airway wall, while edema was also shown in distal parts.

Next, we compared the acute OCT effects in directly BT-treated airways with the 6 weeks earlier BT-treated airways of the RLL and the non-BT-treated RML (as control). All 3 patterns of acute effects were identified in a lower proportion of the RLL airways 6 weeks after treatment: 9 of 29 (31\%) airways showed bronchial wall edema, 18 of 29 (62\%) showed peribronchial edema, and 1/29 (3\%) showed signs of epithelial sloughing (Table 2). For bronchial wall edema, the low-intensity scattering pattern of edema was less pronounced (dark grey instead of black) (Fig. 3b), compared to OCT-imaged airways immediately after treatment (Fig. 3a). In the untreated airways of the RML, bronchial edema was present in only $1 / 3$ of patients and in these $1 / 3$ less pronounced as compared to the peribronchial edema seen in upper lobe airways directly after BT treatment. Epithelial sloughing did not occur in untreated airways (Table 2).

The OCT-detected BT effects in the different bronchial wall layers could not be distinguished on corresponding reconstructed CT images (Fig. 2f). Consistent with previous published reports by this group and others [9, 10], on CT peribronchial consolidations were seen directly after BT and this CT pattern in these airway segments corresponded with the (peri)bronchial edema pattern seen on OCT imaging. Due to the limited resolution of reconstructed CT and/or CT analysis software, no direct correlation with the OCT pattern of epithelial sloughing and any pattern in the smaller airways could be made.

\section{Discussion}

This OCT imaging study is the first study showing that OCT is safe and feasible in a cohort of severe asthmatic patients. Three distinct OCT patterns directly after BT treatment were identified: 2 low-intensity scattering patterns corresponding to bronchial and peribronchial ede- 

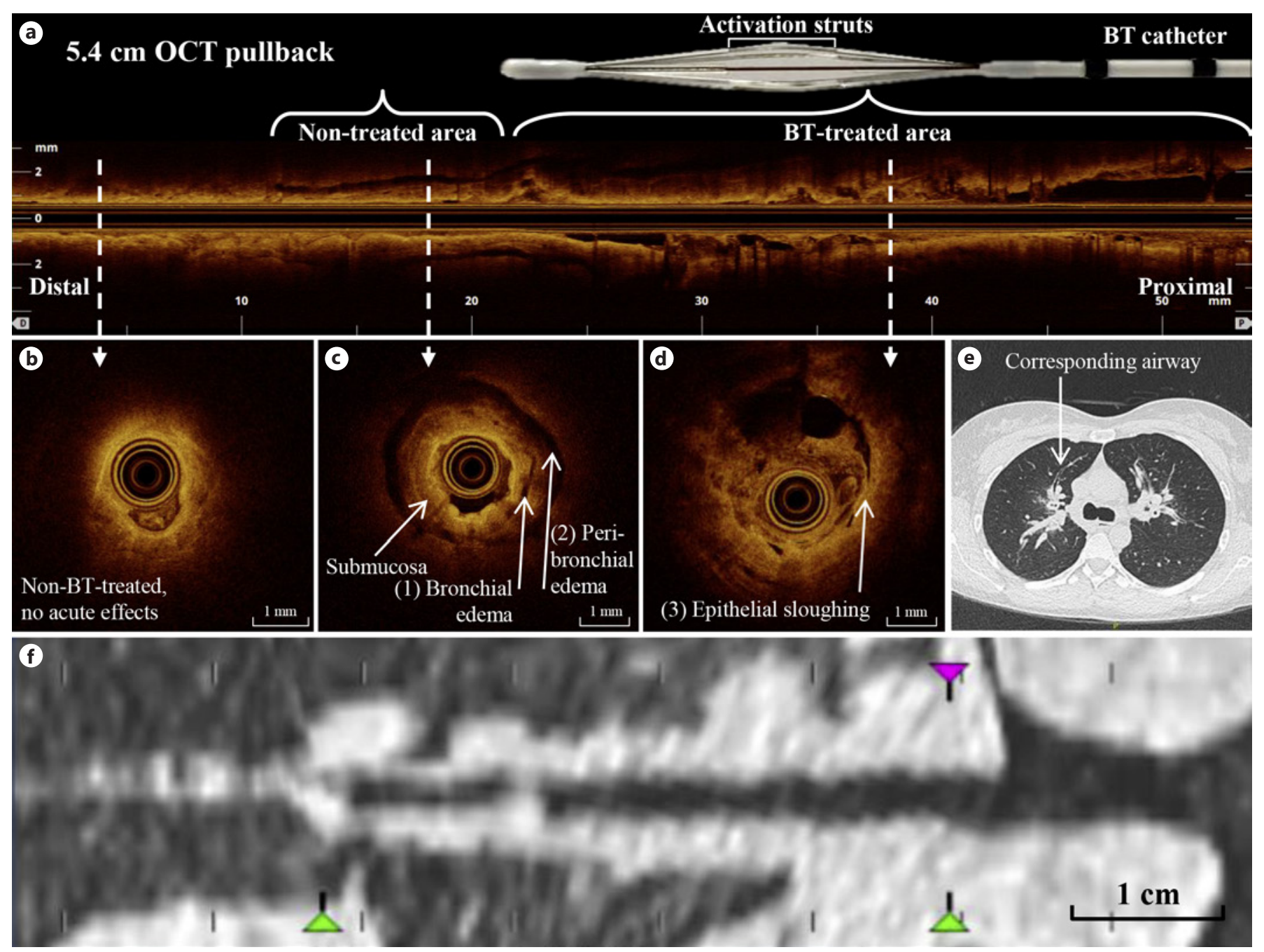

Fig. 2. Optical coherence tomography (OCT) characteristics in comparison to computed tomography (CT) in the anterior segment of the right upper lobe (RB3) after bronchial thermoplasty (BT). a Pullback of $5.4 \mathrm{~cm}$ with an airway diameter of $\sim 1$ to 3.5 $\mathrm{mm}$. b A non-BT-treated airway area without acute effects of BT. c A distal non-BT-treated airway area with (1) bronchial and (2) peribronchial edema. d Epithelial sloughing in a directly BT-treated area. e CT image directly after BT showing peribronchial consolidations in RB3 corresponding to the OCT pullback. $\mathbf{f}$ Reconstructed CT image showing the same airway segment as in a-d.

Table 2. OCT patterns after BT

\begin{tabular}{|c|c|c|c|}
\hline OCT patterns & $\begin{array}{l}\text { Acute airways } \\
\text { (RUL or LUL) } \\
14 \text { airways }\end{array}$ & $\begin{array}{l}6 \text { weeks after BT } \\
\text { (RLL) } \\
29 \text { airways }\end{array}$ & $\begin{array}{l}\text { Untreated } \\
\text { (RML) } \\
14 \text { airways }\end{array}$ \\
\hline Low-intensity scattering pattern of bronchial edema & $13(93)$ & $9(31)$ & $5(36)$ \\
\hline Low-intensity scattering pattern of peribronchial edema & $11(79)$ & $18(62)$ & $2(14)$ \\
\hline High-intensity scattering pattern of epithelial sloughing & $11(79)$ & $1(3)$ & $0(0)$ \\
\hline
\end{tabular}

Findings presented as $n$ (\%). BT, bronchial thermoplasty; OCT, optical coherence tomography; RUL, right upper lobe; LUL, left upper lobe; RLL, right lower lobe; RML, right middle lobe. 

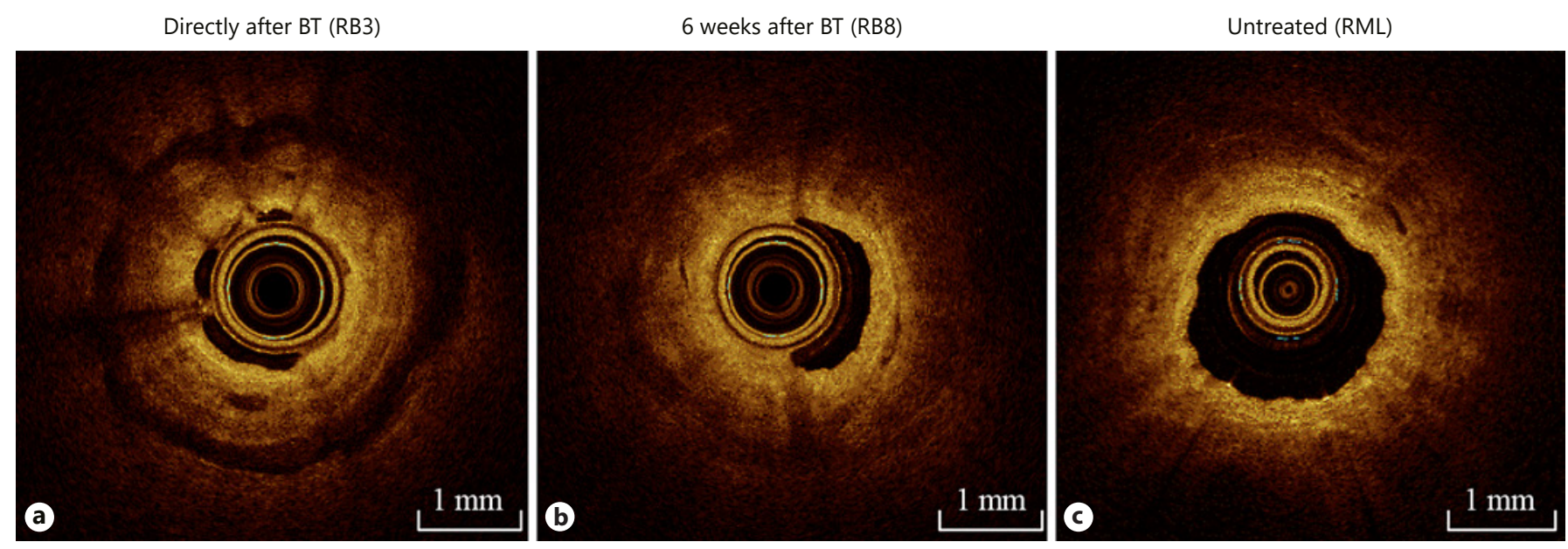

Fig. 3. Optical coherence tomography (OCT) imaging immediately and 6 weeks after bronchial thermoplasty (BT) of BT-treated airways and of the untreated RML. OCT images captured in 1 procedure, in 1 patient, of the anterior segment of the right upper lobe (RB3) immediately after BT (a); the anterior basal segment (RB8) of the right lower lobe 6 weeks after treatment (b); and the BT-untreated right middle lobe (RML) (c).

ma and 1 high-intensity scattering pattern of epithelial sloughing. These patterns extended beyond the BT-targeted ASM layer and diminished over time. Interestingly, OCT-imaged acute BT treatment effects were detected distal to the directly BT-treated airway areas extending to the smaller airways.

Almost all airways directly after BT showed a pattern of edema and epithelial sloughing. In the untreated RML, edema was also present in a substantial but reduced proportion, less pronounced, and without signs of epithelial damage. None of these effects were seen in earlier published OCT data in asthmatic $[16,23]$ and non-asthmatic airways $[12,15]$, indicating that the identified effects were most likely related to BT treatment. The identified acute OCT effects in airways directly treated with BT are in line with previously published CT imaging studies in severe asthma patients in which CT was performed immediately after BT and peribronchial consolidations with ground glass opacities were described in almost all treated lobes $[9,10]$. This study shows acute effects of BT not only in directly BT-treated airway areas but also in more distal non-BT-treated airway areas.

OCT imaging showed abnormalities in non-BT-treated airways, a phenomenon which also has been observed on CT imaging after BT $[9,10]$. There are several hypotheses formulated explaining non-BT-treated acute effects detected on CT: a heat shock effect along the bronchial tree, heat extension through (incomplete) fissures or distribution of mucus, blood, and secretions to the lower lobes as a result of BT treatment in the upper lobes [10, 24]. In the absence of histology directly after BT, it is uncertain which mechanism is correct. Moreover, it is unclear whether the described effects contribute to treatment response or should be considered a side effect of treatment. One study has shown a decrease of ASM after BT in the untreated RML, suggesting that the effect seen in the RML might contribute to treatment response [5]. These results, however, could not be confirmed in a subsequent larger study [4]. Histology studies are needed to assess whether untreated distal airway areas are affected by BT as well.

The described OCT patterns were less pronounced in the airways imaged 6 weeks after BT. This corresponds to the results of a previous study in which, based on histology of lobectomy samples, epithelial sloughing was found in 3 out of 8 non-asthmatic patients 3 weeks after BT [25], while another study showed no signs of epithelial damage 3 months after BT [4]. It is therefore plausible that epithelial damage is a direct effect of BT and resolves within 3-6 weeks. The repair or regeneration of the airway wall epithelium after being disrupted by BT could potentially contribute to the increased epithelial integrity 6 weeks after BT, found in a recent published study [26].

While the mechanism of action of BT is incompletely understood, several elements of the airway wall have been postulated to influence treatment response to BT [27]. By demonstrating a BT effect with OCT imaging in the mucosa, submucosa, and peribronchial area of the airway 
wall, it is well possible that the structures within these layers, such as the epithelium, ASM, and nerves, are modulated by BT. Additionally, small airway dysfunction is of importance in the pathophysiology of asthma [28]. By showing a BT treatment effect in the distal parts of the BT-treated airways, the OCT findings suggest that BT treatment might also have an impact on the smaller airways.

A limitation of this study is that the untreated RML was originally designed as the control but unexpectedly showed effects of treatment as well. One could argue whether the shown effects were a result of BT treatment alone or if they could also appear after manipulation of asthmatic airways with a bronchoscope, although the RML was not manipulated during BT itself. Indeed, the majority of airways of the RML did not show OCT patterns of edema, making it more plausible that the observed effects are a result of being adjacent to the treated upper lobes as described in previous CT studies. This could also explain the earlier reported less prominent decrease of ASM in the untreated RML [4]. Strong points of the current data are the large sample size and detailed high-resolution airway wall imaging in various stages after BT treatment during 1 session. Additionally, by performing both CT and OCT imaging after BT, it was pos- sible to compare, in several airways, both techniques, thereby showing the additional value of more detailed real-time imaging of the airway wall by OCT when compared to CT.

In conclusion, this study showed that OCT is feasible and safe in severe asthmatic patients. Three patterns of acute BT effects were identified corresponding to a lowintensity scattering pattern of (peri)bronchial edema and a high-intensity scattering pattern of epithelial sloughing. OCT was able to assess the acute effects of BT on the airways in more detail than CT and showed an effect in distal non-BT-treated airway areas and to a lesser extent in the non-BT-treated RML as well. Whether these effects contribute to treatment response remains to be investigated.

\section{Disclosure Statement}

The TASMA study is funded by the Dutch Lung Foundation (grant No. 5.2.13.064JO), The Netherlands Organization for Health Research and Development (ZonMw) (grant No. 90713477). Dr. P.I. Bonta and Dr. J.T. Annema received grants and material support from Boston Scientific to conduct the TASMA study (ClinicalTrials.gov; No. NCT02225392). P.I. Bonta has received institutional fees for lectures from Boston Scientific. The other authors declare no potential conflict of interest.

\section{References}

1 Chung KF, Wenzel SE, Brozek JL, Bush A, Castro M, Sterk PJ, Adcock IM, Bateman ED, Bel EH, Bleecker ER, Boulet LP, Brightling C, Chanez P, Dahlen SE, Djukanovic R, Frey U, Gaga M, Gibson P, Hamid Q, Jajour NN, Mauad T, Sorkness RL, Teague WG: International ERS/ATS guidelines on definition, evaluation and treatment of severe asthma. Eur Respir J 2014;43:343-373.

2 Chakir J, Haj-Salem I, Gras D, Joubert P, Beaudoin EL, Biardel S, Lampron N, Martel S, Chanez P, Boulet LP, Laviolette M: Effects of bronchial thermoplasty on airway smooth muscle and collagen deposition in asthma. Ann Am Thorac Soc 2015;12:1612-1618.

3 Denner DR, Doeing DC, Hogarth DK, Dugan K, Naureckas ET, White SR: Airway inflammation after bronchial thermoplasty for severe asthma. Ann Am Thorac Soc 2015;12: 1302-1309.

4 Pretolani M, Bergqvist A, Thabut G, Dombret MC, Knapp D, Hamidi F, Alavoine L, Taille C, Chanez P, Erjefalt JS, Aubier M: Effectiveness of bronchial thermoplasty in patients with severe refractory asthma: clinical and histopathologic correlations. J Allergy Clin Immunol 2017;139:1176-1185.
5 Pretolani M, Dombret MC, Thabut G, Knap D, Hamidi F, Debray MP, Taille C, Chanez P, Aubier M: Reduction of airway smooth muscle mass by bronchial thermoplasty in patients with severe asthma. Am J Respir Crit Care Med 2014;190:1452-1454.

6 Castro M, Rubin AS, Laviolette M, Fiterman J, De Andrade Lima M, Shah PL, Fiss E, Olivenstein R, Thomson NC, Niven RM, Pavord ID, Simoff M, Duhamel DR, McEvoy C, Barbers R, Ten Hacken NH, Wechsler ME, Holmes M, Phillips MJ, Erzurum S, Lunn W, Israel E, Jarjour N, Kraft M, Shargill NS, Quiring J, Berry SM, Cox G; AIR2 Trial Study Group: Effectiveness and safety of bronchial thermoplasty in the treatment of severe asthma: a multicenter, randomized, double-blind, sham-controlled clinical trial. Am J Respir Crit Care Med 2010;181: 116-124.

7 Cox G, Thomson NC, Rubin AS, Niven RM, Corris PA, Siersted HC, Olivenstein R, Pavord ID, McCormack D, Chaudhuri R, Miller JD, Laviolette M; AIR2 Trial Study Group: Asthma control during the year after bronchial thermoplasty. N Engl J Med 2007;356: 1327-1337.
8 Pavord ID, Cox G, Thomson NC, Rubin AS Corris PA, Niven RM, Chung KF, Laviolette M; RISA Trial Study Group: Safety and efficacy of bronchial thermoplasty in symptomatic, severe asthma. Am J Respir Crit Care Med 2007;176:1185-1191.

9 d'Hooghe JNS, van den Berk IAH, Annema JT, Bonta PI: Acute radiological abnormalities after bronchial thermoplasty: a prospective cohort trial. Respiration 2017;94:258262.

10 Debray MP, Dombret MC, Pretolani M, Thabut G, Alavoine L, Brillet PY, Taille C, Khalil A, Chanez P, Aubier M: Early computed tomography modifications following bronchial thermoplasty in patients with severe asthma. Eur Respir J 2017;49:1601565.

11 Coxson HO, Quiney B, Sin DD, Xing L, McWilliams AM, Mayo JR, Lam S: Airway wall thickness assessed using computed tomography and optical coherence tomography. Am J Respir Crit Care Med 2008;177:1201126. 
12 Ding M, Chen Y, Guan WJ, Zhong CH, Jiang M, Luo WZ, Chen XB, Tang CL, Tang Y, Jian QM, Wang W, Li SY, Zhong NS: measuring airway remodeling in patients with different COPD staging using endobronchial optical coherence tomography. Chest 2016;150: 1281-1290.

13 Huang D, Swanson EA, Lin CP, Schuman JS, Stinson WG, Chang W, Hee MR, Flotte T, Gregory K, Puliafito CA, et al: Optical coherence tomography. Science 1991;254:11781181.

14 Chen Y, Ding M, Guan WJ, Wang W, Luo WZ, Zhong CH, Jiang M, Jiang JH, Gu YY, Li SY, Zhong NS: Validation of human small airway measurements using endobronchial optical coherence tomography. Respir Med 2015; 109:1446-1453.

15 d'Hooghe JNS, Goorsenberg AWM, de Bruin DM, Roelofs J, Annema JT, Bonta PI: Optical coherence tomography for identification and quantification of human airway wall layers. PLoS One 2017;12:e0184145.

16 Kirby M, Ohtani K, Lopez Lisbona RM, Lee AM, Zhang W, Lane P, Varfolomeva N, Hui L, Ionescu D, Coxson HO, MacAulay C, FitzGerald JM, Lam S: Bronchial thermoplasty in asthma: 2-year follow-up using optical coherence tomography. Eur Respir J 2015;46: 859-862.

17 Bousquet J, Mantzouranis E, Cruz AA, AitKhaled N, Baena-Cagnani CE, Bleecker ER, Brightling CE, Burney P, Bush A, Busse WW, Casale TB, Chan-Yeung M, Chen R, Chowdhury B, Chung KF, Dahl R, Drazen JM, Fabbri LM, Holgate ST, Kauffmann F, Haahtela T,
Khaltaev N, Kiley JP, Masjedi MR, Mohammad Y, O'Byrne P, Partridge MR, Rabe KF, Togias A, van Weel C, Wenzel S, Zhong N, Zuberbier T: Uniform definition of asthma severity, control, and exacerbations: document presented for the World Health Organization Consultation on Severe Asthma. J Allergy Clin Immunol 2010;126:926-938.

18 Bel EH, Sousa A, Fleming L, Bush A, Chung KF, Versnel J, Wagener AH, Wagers SS, Sterk $\mathrm{PJ}$, Compton $\mathrm{CH}$; Unbiased Biomarkers for the Prediction of Respiratory Disease Outcome (U-BIOPRED) Consortium, Consensus Generation: Diagnosis and definition of severe refractory asthma: an international consensus statement from the Innovative Medicine Initiative (IMI). Thorax 2011;66:910917.

19 d'Hooghe JNS, Ten Hacken NHT, Weersink EJM, Sterk PJ, Annema JT, Bonta PI: Emerging understanding of the mechanism of action of bronchial thermoplasty in asthma. Pharmacol Ther 2018;181:101-107.

20 Cox G, Miller JD, McWilliams A, Fitzgerald JM, Lam S: Bronchial thermoplasty for asthma. Am J Respir Crit Care Med 2006;173: 965-969.

21 Bonta PI, Chanez P, Annema JT, Shah PL, Niven R: Bronchial thermoplasty in severe asthma: best practice recommendations from an expert panel. Respiration 2018, DOI $10.1159 / 000488291$.

22 d'Hooghe JN, Eberl S, Annema JT, Bonta PI: Propofol and remifentanil sedation for bronchial thermoplasty: a prospective cohort trial. Respiration 2017;93:58-64.
23 Adams DC, Hariri LP, Miller AJ, Wang Y, Cho JL, Viliger M, Holz JA, Szabari MV, Hamilos DL, Scott Harris R, Griffith JW, Bouma BE, Luster AD, Medoff BD, Suter MJ: Birefringence microscopy platform for assessing airway smooth muscle structure and function in vivo. Sci Transl Med 2016;8:359ra131.

24 d'Hooghe JNS, Bonta PI, van den Berk IAH, Annema JT: Radiological abnormalities following bronchial thermoplasty: is the pathophysiology understood? Eur Respir J 2017; 50: 1701537.

25 Miller JD, Cox G, Vincic L, Lombard CM, Loomas BE, Danek CJ: A prospective feasibility study of bronchial thermoplasty in the human airway. Chest 2005;127:1999-2006.

26 Chernyavsky IL, Russell RJ, Saunders RM, Morris GE, Berair R, Singapuri A, Chachi L, Mansur AH, Howarth PH, Dennison P, Chaudhuri R, Bicknell S, Rose FRAJ, Siddiqui $S$, Brook BS, Brightling CE: In vitro, in silico and in vivo study challenges the impact of bronchial thermoplasty on acute airway smooth muscle mass loss. Eur Respir J 2018; 51:1701680.

27 d'Hooghe JNS, Ten Hacken NHT, Weersink EJM, Sterk PJ, Annema JT, Bonta PI: Emerging understanding of the mechanism of action of bronchial thermoplasty in asthma. J Pharmacol Ther 2017;181:101-107.

28 van der Wiel E, ten Hacken NH, Postma DS, van den Berge M: Small-airways dysfunction associates with respiratory symptoms and clinical features of asthma: a systematic review. J Allergy Clin Immunol 2013;131:646657. 